\title{
Characterizing rainfall erosivity by kinetic power - Median volume diameter relationship
}

\author{
Francesco G. Carollo $^{a}$, Maria A. Serio ${ }^{a, *}$, Vito Ferro ${ }^{b}$, Artemi Cerdàc \\ ${ }^{a}$ Department of Agricultural, Food and Forestry Sciences, University of Palermo, Italy \\ ${ }^{\mathrm{b}}$ Department of Earth and Marine Science, University of Palermo, Italy \\ ${ }^{\mathrm{c}}$ Soil Erosion and Degradation Research Team, Department of Geography, University of Valencia, Spain
}

\section{A R T I C L E I N F O}

\section{Keywords:}

Rainfall erosivity

Rainfall kinetic power

Raindrop size distribution

Rainfall intensity

Median volume diameter

\begin{abstract}
A B S T R A C T
Kinetic power, i.e. kinetic energy per unit time and area, is the variable widely used to represent the rainfall erosivity which affects soil loss and sediment yield. This paper shows the results of an experimental investigation using the raindrop size distributions (DSDs) measured by an optical disdrometer installed at the Department of Agricultural, Food and Forestry Sciences of University of Palermo in Italy (June 2006-March 2014) and at the El Teularet experimental station in Spain (July 2015-May 2016). At first an analysis of the DSDs aggregated into intensity classes is carried out, then the measured kinetic power values are determined. The aggregated DSDs allowed to establish that the median volume diameter of the distribution is affected by raindrops characterized by the greatest values of the diameters that composes precipitation. The measured kinetic power values allowed to verify the reliability of kinetic power-rainfall intensity relationships proposed by Wischmeier and Smith and Kinnell. Finally, using all the available measurements of kinetic power, rainfall intensity and median volume diameter obtained in different climatic contexts and by different measurement techniques, this paper demonstrates that the ratio between kinetic power and rainfall intensity depends strictly only on median volume diameter of the distribution according to a single site-independent relationship. Therefore the estimate of the kinetic energy per unit volume of rainfall does not require the knowledge of the whole drop size distribution. The reliability of a theoretical relationship relating the kinetic power per unit volume of rainfall to median volume diameter is also positively verified using all available measurements.
\end{abstract}

\section{Introduction}

The kinetic energy of a given rainfall event represents the total energy which is available to detach soil particles through rain splash (Fornis et al., 2005). The understanding of rainfall characteristics such as Drop Size Distribution (DSD), intensity and kinetic energy is important for the prediction of soil erosion (Meshesha et al., 2014). Despite their importance, not all of these rainfall characteristics are among commonly measured meteorological variables, so researchers have empirically related more easily available measurements, such as rainfall intensity, to rain kinetic energy (Angulo-Martínez et al., 2016).

Rainfall kinetic power, $P_{n}$ is the kinetic energy per unit time and area $\left(\mathrm{J} \mathrm{m}^{-2} \mathrm{~s}^{-1}\right)$ and is a hydrological variable used to characterize the erosive power of a rainfall (Nunes et al., 2016), i.e. the rainfall ability to detach and transport soil particles (Cerdà, 1997; Lim et al., 2015).

Many researchers propose empirical relationships linking kinetic power to rainfall intensity having different mathematical forms (Hudson, 1965; Kinnell, 1973; Wischmeier and Smith, 1978; Brown and
Foster, 1987; Sempere-Torres et al., 1992; Coutinho and Tomás, 1995; McGregor et al., 1995; Renard et al., 1997; Uijlenhoet and Stricker, 1999; Jayawardena and Rezaur, 2000; Salles et al., 2002).

The most commonly used relationship for estimating $P_{n}\left(\mathrm{~J} \mathrm{~m}^{-2} \mathrm{~s}^{-1}\right)$ is that proposed by Wischmeier and Smith (1978):

$\frac{P_{n}}{I}=(11.9+8.73 \log I)$

in which $I(\mathrm{~mm} / \mathrm{h})$ is the rainfall intensity. Eq. (1) can be applied for rainfall intensity values $I \leq I_{t}$, being $I_{t}$ the intensity threshold value which Wischmeier and Smith (1978) set equal to $76 \mathrm{~mm} / \mathrm{h}$. Wischmeier and Smith (1978) also state that for $I>I_{t}$ the ratio $P_{n} / I\left(\mathrm{~J} \mathrm{~m}^{-2} \mathrm{~mm}^{-1}\right)$ assumes the constant value, calculated by Eq. (1), equal to $28.3 \mathrm{~J} \mathrm{~m}^{-2} \mathrm{~mm}^{-1}$.

In other words the ratio $P_{n} / I$, which represents the kinetic energy per unit volume of rainfall, increases for rainfall intensity value less than or equal to $I_{t}$ (Eq. (1)) and it becomes constant (Eq. (1)) for rainfall intensity greater than $I_{t}$.

\footnotetext{
* Corresponding author.

E-mail address: mariaangela.serio@unipa.it (M.A. Serio).
} 
Wischmeier and Smith (1978) justify this threshold value suggesting that the median volume diameter, $D_{0}$, which is the diameter that divides the DSD in two parts of equal volume, stops to continue to increase when rainfall intensities exceed $76 \mathrm{~mm} / \mathrm{h}$.

For describing the same trend Kinnell (1981) proposes the following relationship:

$\frac{P_{n}}{I}=a(1-b \exp (-c I))$

where $a, b$ and $c$ are parameters. According to Eq. (2) $P_{n} / I$ has a finite positive value at zero intensity and approaches to the asymptotic value $a$ at high intensity values. Kinnell (1981) states that $a$ parameter can be assumed equal to $29 \mathrm{~J} \mathrm{~m}^{-2} \mathrm{~mm}^{-1}$ while $b$ and $c$ parameters are sitespecific (Salles et al., 2002).

As suggested by Brown and Foster (1987), Eq. (2) is used in the RUSLE model with $a=29 \mathrm{~J} \mathrm{~m}^{-2} \mathrm{~mm}^{-1}, \quad b=0.72$ and $c=0.05 \mathrm{~h} \mathrm{~mm}^{-1}$. This choice allows to obtain an asymptotic value of $P_{n} / I$, which is near to the value obtained by Eq. (1) for $I>76 \mathrm{~mm} / \mathrm{h}$ $\left(P_{n} / I=28.3 \mathrm{~J} \mathrm{~m}^{-2} \mathrm{~mm}^{-1}\right)$. For estimating the rainfall kinetic power Foster (2004) in the RUSLE2 model, suggests the use of Eq. (2) with parameter values proposed by McGregor et al. (1995), i.e. $a=29 \mathrm{~J} \mathrm{~m}^{-2} \mathrm{~mm}^{-1}, \quad b=0.72$ and $c=0.082 \mathrm{~h} \mathrm{~mm}^{-1}$. Other researchers (Coutinho and Tomás, 1995; Cerro et al., 1998; Jayawardena and Rezaur, 2000) suggest values of $a$ parameter $>29 \mathrm{~J} \mathrm{~m}^{-2} \mathrm{~mm}^{-1}$ and dependent on geographical location.

Assouline and Mualem (1989) use the Weibull function, as DSD calibrated for five different locations, and the raindrop terminal velocity equation proposed by Mualem and Assouline (1986), for deducing the relationship between the kinetic energy per unit mass and rainfall intensity. The different curves corresponding to the five sites show notable differences and the kinetic energy per unit mass might be represented by a monotonically increasing function or might reach a maximum value and then it could decline for higher rainfall intensity.

Salles et al. (2002), carrying out an overview of many empirical relationships $P_{n}-I$, show that, for a fixed rainfall intensity, these relationships yield to very different values of kinetic power. Salles et al. (2002) in agreement with Parsons and Gadian (2000), conclude that a global parameter, as rainfall intensity $I$ or median volume diameter $D_{0}$, is not sufficient to characterize rainfall erosivity since kinetic power measurements are also dependent on other effect such as rain type, altitude, climate and method of measurement.

Carollo and Ferro (2015), using about 24000 DSDs detected at Palermo (South Italy) by an optical disdrometer, show that: i) Eq. (1) is fully applicable to rainfall recorded in Sicily; ii) Eq. (2) underestimates the measured $P_{n}$ values for low rainfall intensity; iii) a power relationship, calibrated by the collected data, overestimates the rainfall kinetic power for high values of $I$.

In this paper at first the analysis of DSD detected by an optical disdrometer installed in two similar climatic environments, i.e. at Palermo (Italy) and at El Teularet (Spain), and aggregated into rainfall intensity classes, is presented. The aggregated DSDs are used to quantify the median volume diameter of the distribution and the kinetic energy per unit volume of rainfall. The capability of the most widely applied empirical relationships to estimate kinetic power by rainfall intensity is verified. Finally the reliability of a theoretically deduced relationship between kinetic energy per unit volume of rainfall and median volume diameter is also tested.

\section{Materials and methods}

\subsection{Measurement techniques and experimental sites}

The DSDs were detected using the same optical disdrometer (model ODM 70 made by Eigenbrodt), installed in two experimental sites located at Palermo (South Italy) and El Teularet (Spain) (Fig. 1).

For each raining minute, the disdrometer measures drop diameter in

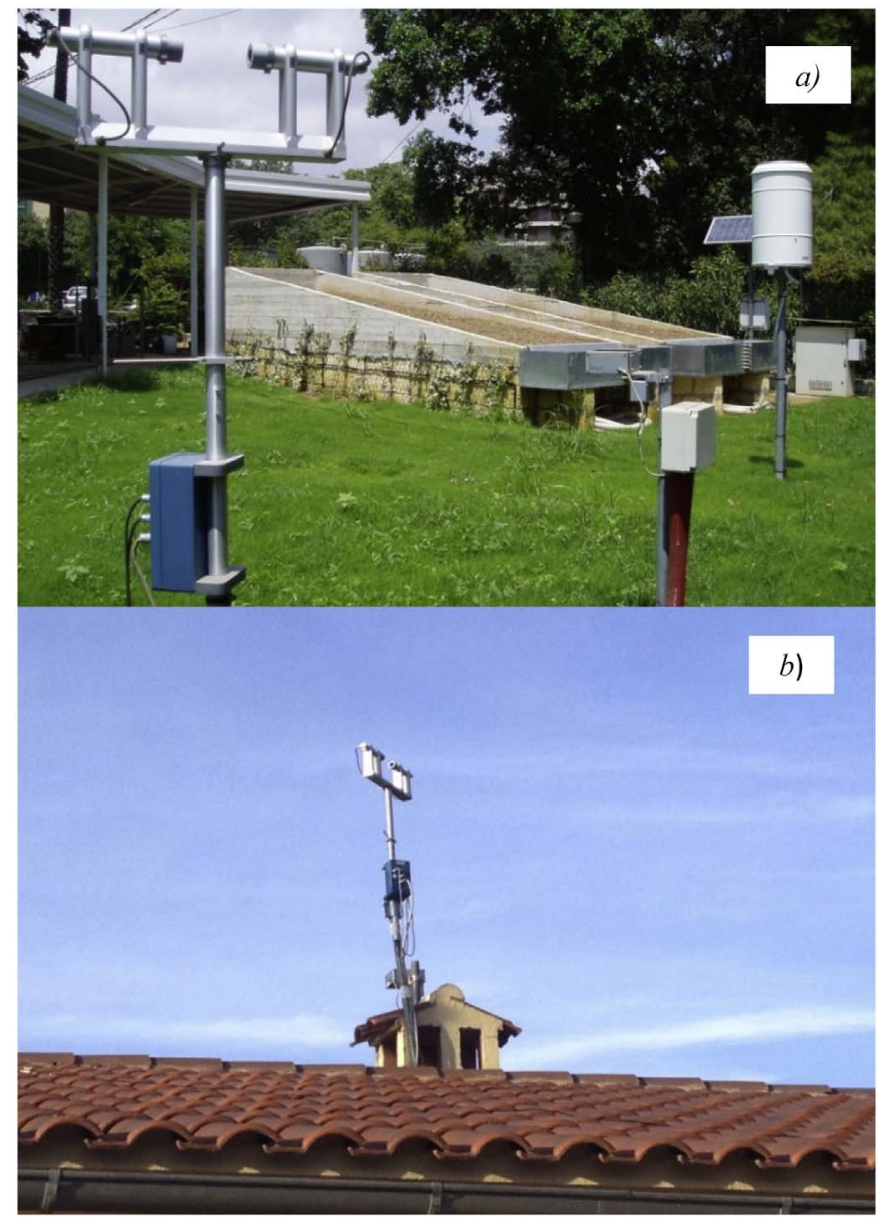

Fig. 1. View of Palermo (a) and El Teularet (b) experimental areas.

the range $0.05-0.6 \mathrm{~cm}$. Each drop is separately measured and registered into classes of about $0.005 \mathrm{~cm}$ width. The disdrometer divides diameter range into 128 classes and gives the number of drops belonging to a particular class for each recording minute. Drop diameter is measured registering light damping due to the passage of the drop in the control volume between two diodes. This volume has cylindrical shape with a length of $12 \mathrm{~cm}$ and a diameter of $2.2 \mathrm{~cm}$. Disdrometer measures simultaneously diameter and falling velocity of the drops that pass through the control volume (Grossklaus et al., 1998; Carollo and Ferro, 2015). The Palermo experimental station is located at the Department of Agricultural, Food and Forestry Sciences of the University of Palermo, at $40 \mathrm{~m}$ a.s.l. (Fig. 1a). The climate is Mediterranean temperate (Köppen's Csa type), characterized by dry and hot summer and mild and rainy winter. The average annual temperatures range between $15^{\circ} \mathrm{C}$ and $22^{\circ} \mathrm{C}$, while rainfalls, mainly concentrated in autumn and winter, show mean annual value of $654 \mathrm{~mm}$.

The El Teularet experimental site is located at Sierra de Enguera at $100 \mathrm{~km}$ southwest from Valencia, at $760 \mathrm{~m}$ a.s.l. (Fig. 1b). Climate is typical Mediterranean with 3-5 months of summer drought, usually from late June to September. Mean annual rainfall at the study area range from $479 \mathrm{~mm}$ at the Enguera-Las Arenas meteorological station to $590 \mathrm{~mm}$ at the Enguera Confederación Hidrográfica del Jucar (CHJ) meteorological station. Rainfall is distributed homogenously among spring, autumn and winter, while the summer is extremely dry due to high temperatures and lack of rainfall (García-Orenes et al., 2009). Mean annual temperature ranges from $12.7^{\circ} \mathrm{C}$ at the Enguera-Las Arenas meteorological station to $14.2^{\circ} \mathrm{C}$ at the Enguera Confederación Hidrográfica del Jucar (CHJ) meteorological station (García-Orenes et al., 2009). 


\subsection{DSD and rainfall energetic characteristics}

The kinetic power of the precipitation can be calculated by adding the contribution of all raindrops that constitute precipitation, once its DSD and the relationship between raindrop terminal velocity and drop diameter are known (Mualem and Assouline, 1986).

The measured rainfall DSD at the ground level is the result of a series of physical phenomena (i.e. raindrop collision, coalescence, break up) that influence raindrop formation and its evolution during its falling process (Assouline and Mualem, 1989). The development of precipitation due to capture and collision of cloud drops plays an important role in the precipitation evolution, but for hydrological studies it is important understand the collisional phenomena between the drops before to reach the soil surface. The collision of rain drops together with the evaporation process, are the main physical mechanism that influence the DSD shape (D'Adderio, 2015).

The study of the DSD formation and evolution is carried out distinguishing two different raindrop size distributions referred to unitary volume of air or to unit area and time. The distribution $N_{v}(D) d D$ represents the number of raindrops with diameters between $D$ and $D+d D$ per unit volume of air, in which $D$ is expressed in $\mathrm{cm}$ and volume in $\mathrm{m}^{3}$ and the units of $N_{v}(D)$ become $\mathrm{cm}^{-1} \mathrm{~m}^{-3}$. According to this definition, the DSD refers to the spatial distribution of raindrops in the air (which governs the raindrop concentration) and to the probability distribution of raindrop sizes in the air.

The second form of the raindrop size distribution, $N(D) d D$, represents the expected number of raindrops with diameters between $D$ and $D+d D$ arriving at a surface per unit area and per unit time, if $D$ is expressed in $\mathrm{cm}$, area in $\mathrm{m}^{2}$ and time in $s$, the units of this distribution $N$ (D) become $\mathrm{cm}^{-1} \mathrm{~m}^{-2} \mathrm{~s}^{-1}$. For hydrological studies, the DSD usually refers to the number of droplets $N(D) \mathrm{d} D$ that reach a unit horizontal area during a unit time (Uijlenhoet and Stricker, 1999) (Carollo and Ferro, 2015).

Uijlenhoet and Stricker (1999) suggest that $N_{v}(D)$ yields to know the static properties of the raindrop population such as its concentration and size distribution. In addition to these static properties, $N(D)$ involves the dynamic properties of the raindrop population as well its velocity distribution. If the effects of wind, turbulence and raindrop interaction are neglected, the two size distributions are related by the following relationship (Hall and Calder, 1993; Uijlenhoet and Stricker, 1999, Carollo and Ferro, 2015):

$N(D) d D=V(D) N_{V}(D) d D$

in which $V(D)$, expressed in $\mathrm{m} \mathrm{s}^{-1}$, is the terminal velocity of the drop having diameter $D(\mathrm{~cm})$.

For studying the energetic characteristics of raindrops that reach the ground area, it is more accurate and physically based referring to $N(D)$ $d D$, i.e. number of raindrops with diameters between $D$ and $D+d D$ arriving at a surface per unit area and per unit time.

One of the most applied drop size distribution, because of its flexibility and its applicability in different climatic conditions, is the Gamma distribution (Ulbrich, 1983), that represents a generalization of exponential distribution (Marshall and Palmer, 1948):

$N_{v}(D) d(D)=N_{0 v} D^{\mu_{v}} \exp \left(-\Lambda_{v} D\right) d D$

in which $\mu_{v}, \Lambda_{v}$ and $N_{0 v}$, are the distribution parameters. If $\mu_{v}$ is equal to zero Eq. (4) gives Marshall-Palmer distribution.

If the following expression (Atlas and Ulbrich, 1977) estimating the drop terminal velocity is used:

$V(D)=17.67 D^{0.67}$

in which $D$ is expressed in $\mathrm{cm}$ and $V$ in $\mathrm{m} \mathrm{s}^{-1}$, by combining Eqs. (3), (4) and (5) the following relationship is obtained:

$N(D) d D=17.67 D^{0.67} N_{0, V} D^{\mu_{V}} \exp \left(-\Lambda_{V} D\right) d D=N_{0} D^{\mu} \exp (-\Lambda D) d D$
Setting $N_{0}=17.67 N_{0, v}, \mu=\mu_{v}+0.67$, and $\Lambda=\Lambda_{v}$, Eq. (6) can be rewritten in the following form:

$N(D) d D=N_{0} D^{\mu} \exp (-\Lambda D) d D$

in which $\mu, \Lambda$ and $N_{0}$, are the distribution parameters.

Taking into account that Eq. (7) has the same mathematical shape of Eq. (4), we can conclude that the DSD of Ulbrich (1983) is also reliable for estimating drop size distribution per unit area and unit time.

Ulbrich (1983) demonstrated that the median volume diameter, $D_{0}$, that is the diameter that divides the distribution in two parts of equal volume can be expressed as:

$\Lambda D_{0}=3.67+\mu$

which is accurate to within $0.5 \%$.

Hudson (1971) proposes a relationship between $D_{0}$ and rainfall intensity for Rhodesian precipitations by a curve that presents a maximum point for $I \approx 80 \mathrm{~mm} / \mathrm{h}$ even if $D_{0}$ values are characterized by a low variability $\left(2.0<D_{0}<2.5 \mathrm{~mm}\right)$ in the explored range of $I$ $(25<I<200 \mathrm{~mm} / \mathrm{h})$. Carter et al. (1974) aggregate the DSDs measured in Louisiana and Mississippi for 13 intensity classes, and found that $D_{0}$ does not increase for rainfall intensities greater than about $65 \mathrm{~mm} / \mathrm{h}$. Many other researches (Laws and Parsons, 1943; Atlas, 1953; Kelkar, 1959; Zanchi and Torri, 1980; Brandt, 1990; Jau-yau et al., 2008) propose a power law for describing the relationship $D_{0}-I$ implying that $D_{0}$ continues to increase indefinitely with $I$. This result is in contrast with other researchers which state that a maximum median volume diameter value is reached at high rainfall intensities (usually above $70-100 \mathrm{~mm} / \mathrm{h}$ ), after which the $D_{0}$ either stabilizes (Kinnell, 1981; Rosewell, 1986; Brown and Foster, 1987; Carollo et al., 2016a) or even decreases (Hudson, 1965; Baruah, 1973; Carter et al., 1974; Assouline and Mualem, 1989; Van Dijk et al., 2002).

Using Eq. (7), rainfall intensity $I(\mathrm{~mm} / \mathrm{h})$ can be calculated from the following expression (Salles et al., 2002; Carollo and Ferro, 2015):

$I=3.6 \frac{\pi}{6} \int_{0}^{\infty} D^{3} N(D) d D=3.6 \frac{\pi}{6} N_{0} \int_{0}^{\infty} D^{3+\mu} \exp (-\Lambda D) d D$

where $D$ is expressed in $\mathrm{cm}$ and $N(D) d D$ in $\mathrm{cm}^{-1} \mathrm{~m}^{-2} \mathrm{~s}^{-1}, \mu, \Lambda$ and $N_{0}$, are the distribution parameters.

Taking into account that (Olver, 1997):

$\int_{0}^{\infty} D^{3+\mu} \exp (-\Lambda D) d D=\frac{\Gamma(4+\mu)}{\Lambda^{4+\mu}}$

being $\Gamma$ the gamma function, Eq. (9) becomes:

$I=3.6 \frac{\pi}{6} N_{0} \frac{\Gamma(4+\mu)}{\Lambda^{4+\mu}}$

Eq. (11) links the DSD parameters $\mu, \Lambda$ and $N_{0}$ to rainfall intensity (Carollo and Ferro, 2015).

Using experimental measurements of raindrop terminal velocity carried out by many researchers (Laws, 1941; Gunn and Kinzer, 1949; Blanchard, 1967; Beard, 1976; Epema and Riezebos, 1983; Jayawardena and Rezaur, 2000), Ferro (2001) proposes the following relationship for estimating the terminal velocity, $V(D)\left(\mathrm{m} \mathrm{s}^{-1}\right)$, of the drop having diameter $D(\mathrm{~cm})$ (Best, 1960; Mualem and Assouline, 1986; Carollo and Ferro, 2015; Carollo et al., 2016a, b):

$V(D)=9.5[1-\exp (-6 D)]$

Taking into account that the kinetic power, $P_{n}\left(\mathrm{~J} \mathrm{~m}^{-2} \mathrm{~s}^{-1}\right)$, knowing both DSD and terminal velocity, can be calculated as (Salles et al., 2002):

$P_{n}=10^{-6} \frac{\rho \pi}{12} \int_{0}^{\infty}[V(D)]^{2} D^{3} N(D) d D$

in which $\rho$ is water density $\left(\mathrm{kg} \mathrm{m}^{-3}\right)$, Carollo and Ferro (2015) demonstrated that, combining Eqs. (7), (12) and (13), the following 
relationship can be deduced:

$P_{n}=10^{-6} \frac{9.5^{2}}{7.2} \rho \Lambda^{4+\mu}\left[\frac{1}{\Lambda^{4+\mu}}-\frac{2}{(6+\Lambda)^{4+\mu}}+\frac{1}{(12+\Lambda)^{4+\mu}}\right] I$

Eq. (14) underlines that rainfall kinetic power can be determined if both the rainfall intensity and $\mu$ and $\Lambda$ parameters of the DSD are known.

The influence of DSD on $P_{n} / I$ values, as Eq. (14) establishes, can be evaluated by fitting Ulbrich's distribution to measured DSD. According to Carollo and Ferro (2015), probability $\mathrm{P}(D)$ that raindrop diameter is less than $\mathrm{D}$ can be calculated by the following relationship:

$P(D)=\frac{\Lambda^{\mu+1}}{\Gamma(\mu+1)} \int_{0}^{D} D^{\mu} \exp (-\Lambda D) d D$

Eq. (15) shows how $P(D)$ is only function of $\mu$ and $\Lambda$ parameters of Ulbrich's distribution.

The median drop diameter, $D_{50}$, of the Ulbrich's distribution can be calculated by the following approximated relationship (Ulbrich, 1983; Uijlenhoet and Stricker, 1999):

$D_{50}=\frac{0.67+\mu}{\Lambda}$

that allows with Eq. (8) to estimate $\mu$ and $\Lambda$ by momentum method (MM):

$\mu=D_{0} \Lambda-3.67$

$\Lambda=\frac{3}{D_{0}-D_{50}}$

Recently, Carollo et al. (2016b) verify the reliability of the Eqs. (1) and (2) using $P_{n}$ values both calculated by 42355 DSDs measured at Palermo and aggregated in intensity classes and those available in literature. They conclude that: (i) a single relationship relating $P_{n}-I$ is not reliable to estimate $P_{n}$ everywhere; (ii) the relationship by Wischmeier and Smith (1978) is applicable for estimating the rainfall kinetic power in Sicilian environment, does not need to be recalibrated and a threshold value of the rainfall intensity $I_{t}$ equal to $40 \mathrm{~mm} / \mathrm{h}$ has to be used.

Uijlenhoet and Stricker (1999) demonstrated that the exponential distribution of Marshall and Palmer (1948), when it is referred to the unit area and time, can be assumed formally identical to Gamma distribution (Ulbrich, 1983) with the parameter $\mu$ equal to 0.67 . According to this last result and using Eqs. (8) and (14) with $\mu=0.67$, Carollo et al. (2016b) deduced theoretically the following relationship $P_{n}-I$ :

$\frac{P_{n}}{I}=\frac{10^{-6} 9.5^{2}}{7.2} \rho\left[1-\frac{2}{\left(6 \frac{D_{0}}{4.34}+1\right)^{4.67}}+\frac{1}{\left(6 \frac{D_{0}}{2.17}+1\right)^{4.67}}\right]$

which establishes that the ratio $P_{n} / I\left(\mathrm{~J} \mathrm{~m}^{-2} \mathrm{~mm}^{-1}\right)$ depends only on median volume diameter $D_{0}$. In other words Eq. (19) states that the diameter $D_{0}$ can be considered representative of the entire DSD when the rainfall kinetic power has to be calculated.

According to Eq. (19), if $D_{0}$ assumes a constant value $P_{n} / I$ assumes a constant value too. In other words, Eq. (19) represents a theoretical confirmation of the Wischmeier and Smith (1978) hypothesis according to which $D_{0}$ does not continue to increase when rainfall intensities exceed a threshold value $(76 \mathrm{~mm} / \mathrm{h}$ for Wischmeier and Smith).

\section{Results and discussions}

\subsection{DSD characterization}

The disdrometer registered 544 rainfall events in the period June 2006-April 2014 at Palermo experimental site, and 79 events at El Teularet experimental site in the period July 2015-May 2016.
For each rainfall event, it was considered only DSDs for which the rainfall intensity was $>0.5 \mathrm{~mm} / \mathrm{h}$ and measured diameter classes were at least 20. This choice allows to exclude both rainfall having a low erosive power and DSDs having a small sample size (Carollo and Ferro, 2015; Carollo et al., 2016a). This procedure provided 45802 DSDs for Palermo and 5537 DSDs for El Teularet with a sampling time of 1 min (named single DSDs) characterized by $I$, determined by Eq. (11), that varies in the range $0.5-203 \mathrm{~mm} / \mathrm{h}$ and $0.7-150 \mathrm{~mm} / \mathrm{h}$ respectively.

In order to highlight the influence of rainfall intensity on rainfall energetic characteristics, because of the dispersion of the data (Laws and Parsons, 1943; Carter et al., 1974; Sauvageot and Lacaux, 1995; Jayawardena and Rezaur, 2000), the single DSDs detected at Palermo and $\mathrm{El}$ Teularet were aggregated into intensity classes having a different range. This choice is justified by a previous analysis (Carollo et al., 2016b) which demonstrates that the available DSDs can be aggregated into rainfall intensity class since the DSDs falling into each class are not statistically different. In particular, the intensity class range was set equal to $1 \mathrm{~mm} / \mathrm{h}$ for $I<30 \mathrm{~mm} / \mathrm{h}, 2 \mathrm{~mm} / \mathrm{h}$ for $30<I<50 \mathrm{~mm} / \mathrm{h}$, $5 \mathrm{~mm} / \mathrm{h}$ for $50<I<100 \mathrm{~mm} / \mathrm{h}$ and $10 \mathrm{~mm} / \mathrm{h}$ for $I>100 \mathrm{~mm} / \mathrm{h}$ (Carollo et al., 2016a). For each class, the rainfall intensity was calculated as average of the intensities of the single DSDs falling into the class.

This procedure yields 59 DSDs for Palermo and 54 for El Teularet experimental sites characterized by rainfall intensity values ranging from 0.8 to $203 \mathrm{~mm} / \mathrm{h}$ and from 0.7 to $145 \mathrm{~mm} / \mathrm{h}$, respectively.

Fig. 2 shows the comparison between drop diameter, $\mathrm{D}_{\mathrm{xx}}$, corresponding to a given percentile, $\mathrm{xx},(25,50,75$ and 99$)$ of the aggregated DSDs versus rainfall intensity. In particular Fig. 2 highlights that the Palermo DSD is different from the one detected at El Teularet. In fact, for a fixed rainfall intensity the precipitation detected at Palermo present $D$ values being characterized by values of $D_{25}$ (Fig. 2a), median diameter, $D_{50}$, (Fig. 2b), $D_{75}$ (Fig. 2c) and $D_{99}$ (Fig. 2d) greater than the El Teularet ones. However for both datasets the $D_{25}$ and the median diameter of the distribution $\left(D_{50}\right)$ seems to be independent of rainfall intensity (Fig. 2). The $D_{75}$ of the DSDs detected in the two experimental sites present a different trend with $I$. In particular referring to Palermo site the drop diameter's 75th percentiles presents an increasing trend with $I$ for the lowest values of rainfall intensity $(I<20 \mathrm{~mm} / \mathrm{h})$ while for $I>20 \mathrm{~mm} / \mathrm{h}$ no clear trend with $I$ can be observed. Instead $\mathrm{El}$ Teularet $D_{75}$ values show an increase trend for all values of rainfall intensity (Fig. 2c).

For Palermo dataset $D_{99}$ shows an increasing trend with $I$ until a threshold value of rainfall intensity equal to $40 \mathrm{~mm} / \mathrm{h}$. For $I>40 \mathrm{~mm} /$ h, $D_{99}$ does not more increase when rainfall intensity increases. For El Teularet dataset, $D_{99}$ increases with $I$ until $I<70 \mathrm{~mm} / \mathrm{h}$. For $I>70 \mathrm{~mm} / \mathrm{h}$ the two datasets are overlapped (Fig. $2 \mathrm{~d}$ ).

Conversely, for a given rainfall intensity value, the median volume diameter, $D_{0}$, of the Sicilian DSD is more similar to the Spanish one (Fig. 3), even if for $I<30 \mathrm{~mm} / \mathrm{h}$ the DSDs detected at El Teularet present lower values of the median volume diameter than the Palermo one. For both datasets the median volume diameter, $D_{0}$, reveals an increasing trend with $I$ until a threshold value of rainfall intensity, $I_{t}$ equal to $40 \mathrm{~mm} / \mathrm{h}$. For $I>I_{t}$, primarily for Palermo dataset, $D_{0}$ does not more increase when rainfall intensity increases (Fig. 3).

Fig. 4 shows the comparison between the median volume diameter and the drop diameter $D_{x x}$ corresponding to the percentile 25, 50, 75 and $99 \%$ of the DSDs detected at Palermo and El Teularet. For the same DSDs, Fig. 5 shows the relationship between $D_{0}$ and the standard deviation, $\sigma(D)(\mathrm{cm})$. The DSD analysis highlights that $D_{0}$ is only correlated to $D_{99}$ (Fig. 4d) according to a site specific relationship.

The DSD measurements allow also to establish that $D_{0}$ is strictly related to the standard deviation of the distribution (Fig. 5) and this relation is dependent on the site where precipitation occurs. These results suggest that: (i) $D_{0}$ is affected by the greatest values of the diameters that composes precipitation; (ii) the median volume diameter can be also considered as a shape parameter of the raindrop size 

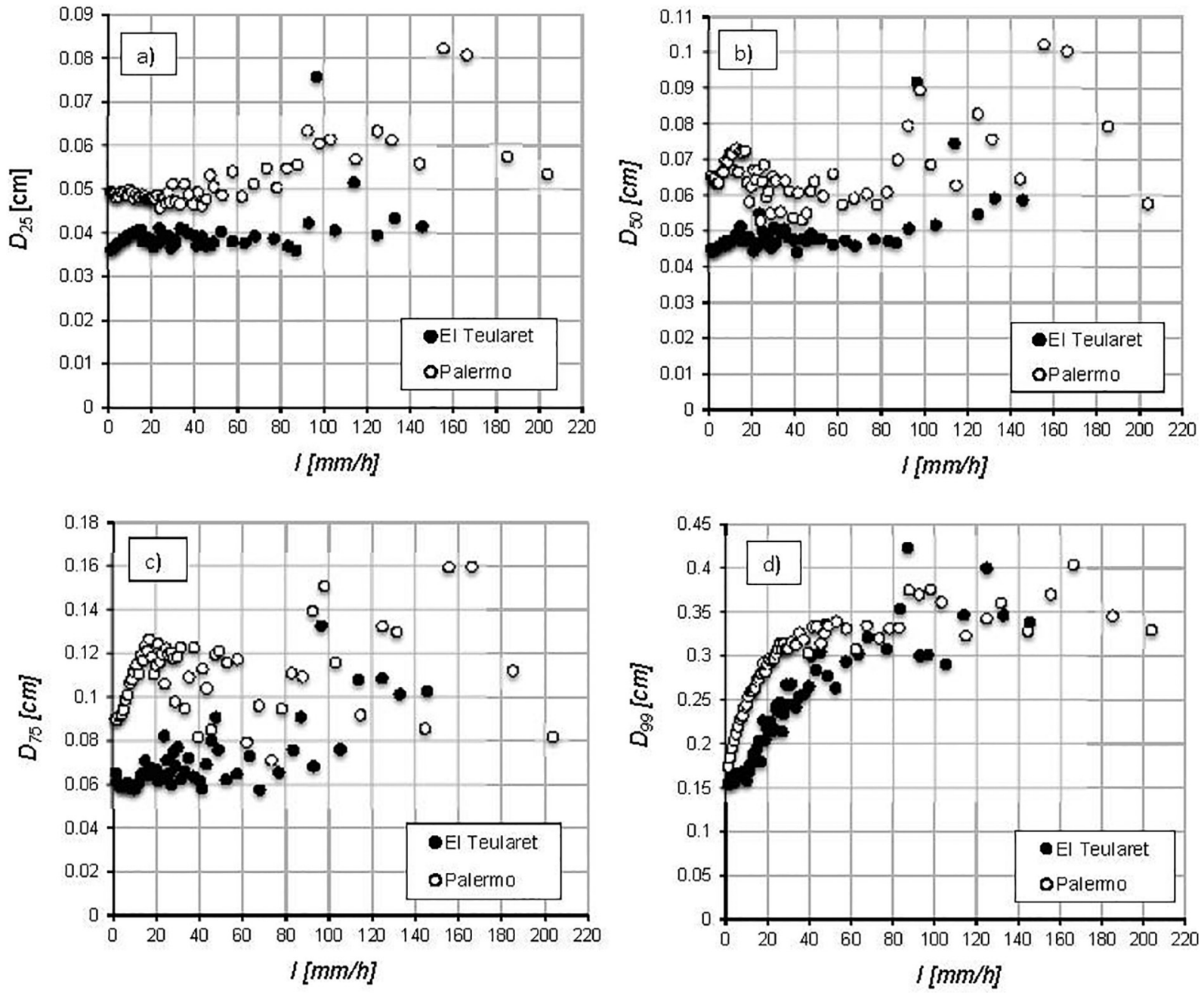

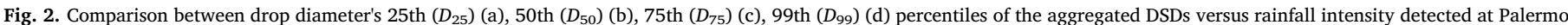
and El Teularet sites.

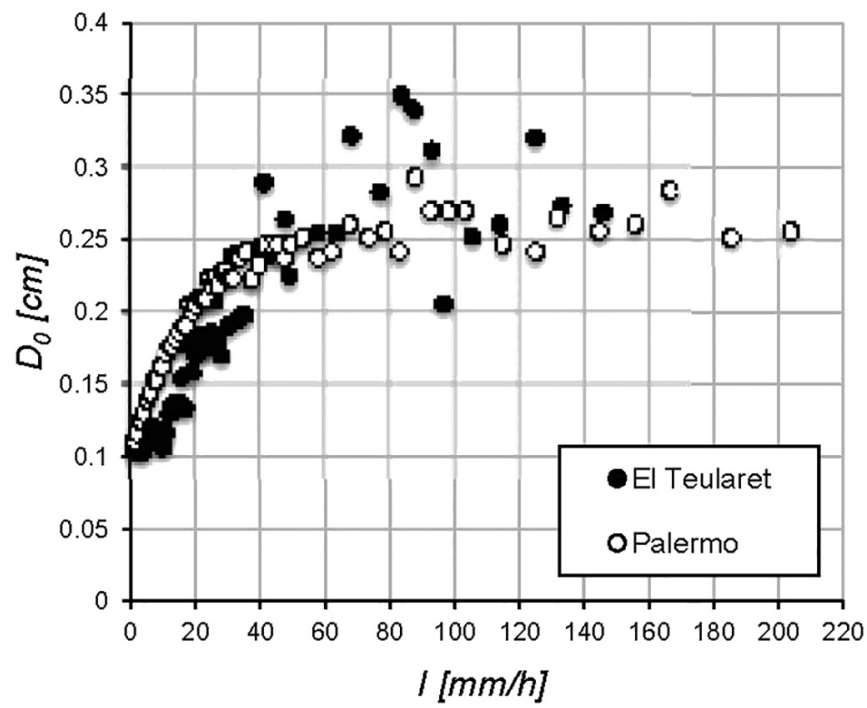

Fig. 3. Comparison between the measured $D_{0}$ values versus rainfall intensity of the aggregated DSDs detected at Palermo and El Teularet sites.

distribution.

The Ulbrich's distribution (Eq. (15)) was fitted to each aggregated DSDs of the present investigation. The two parameters, $\mu$ and $\Lambda$, were estimated by the maximum likelihood method (ML) and momentum method (MM) (Eqs. (17) and (18)) (Fig. 6). For each estimate method, Fig. 6 shows examples of fitting of Eq. (15) to DSDs detected at Palermo and El Teularet corresponding to different rainfall intensities. The Ulbrich's distribution resulted reliable to reproduce the raindrop size distribution at both sites. Fig. 6 highlights that, as it is expected, the ML method gives the best fit even if the MM method allows to obtain also accurate results.

\subsection{Rainfall energetic characteristics and reliability of kinetic power relationships}

For each aggregated DSD measured at Palermo and El Teularet, the value of the kinetic power, $P_{n}$, was estimated by coupling at each diameter its terminal velocity calculated by Eq. (12).

The comparison between the pairs $\left(I, P_{n} / I\right)$ detected at Palermo and El Teularet (Fig. 7) highlights that the pairs $\left(I, P_{n} / I\right)$ are quasi-overlapped for $I>30 \mathrm{~mm} / \mathrm{h}$, while for $\mathrm{I}<30 \mathrm{~mm} / \mathrm{h}$ the Palermo $P_{n} / I$ values are greater than El Teularet ones. However the pairs $\left(I, P_{n} / I\right)$ of the two datasets show the same trend with rainfall intensity. In particular as the trend of $D_{0}$ with $I$, in both sites the kinetic energy per unit volume of rainfall $\left(P_{n} / I\right)$ increases with rainfall intensity until $I=40 \mathrm{~mm} / \mathrm{h}$ and for $I>40 \mathrm{~mm} / \mathrm{h}$ it varies around a quasi-constant value. This trend can be physically justified taking into account the phenomena of aggregation (collapse) and disaggregation of the raindrops. For $I \leq I_{t}$ an increase of rainfall intensity determines an increase 

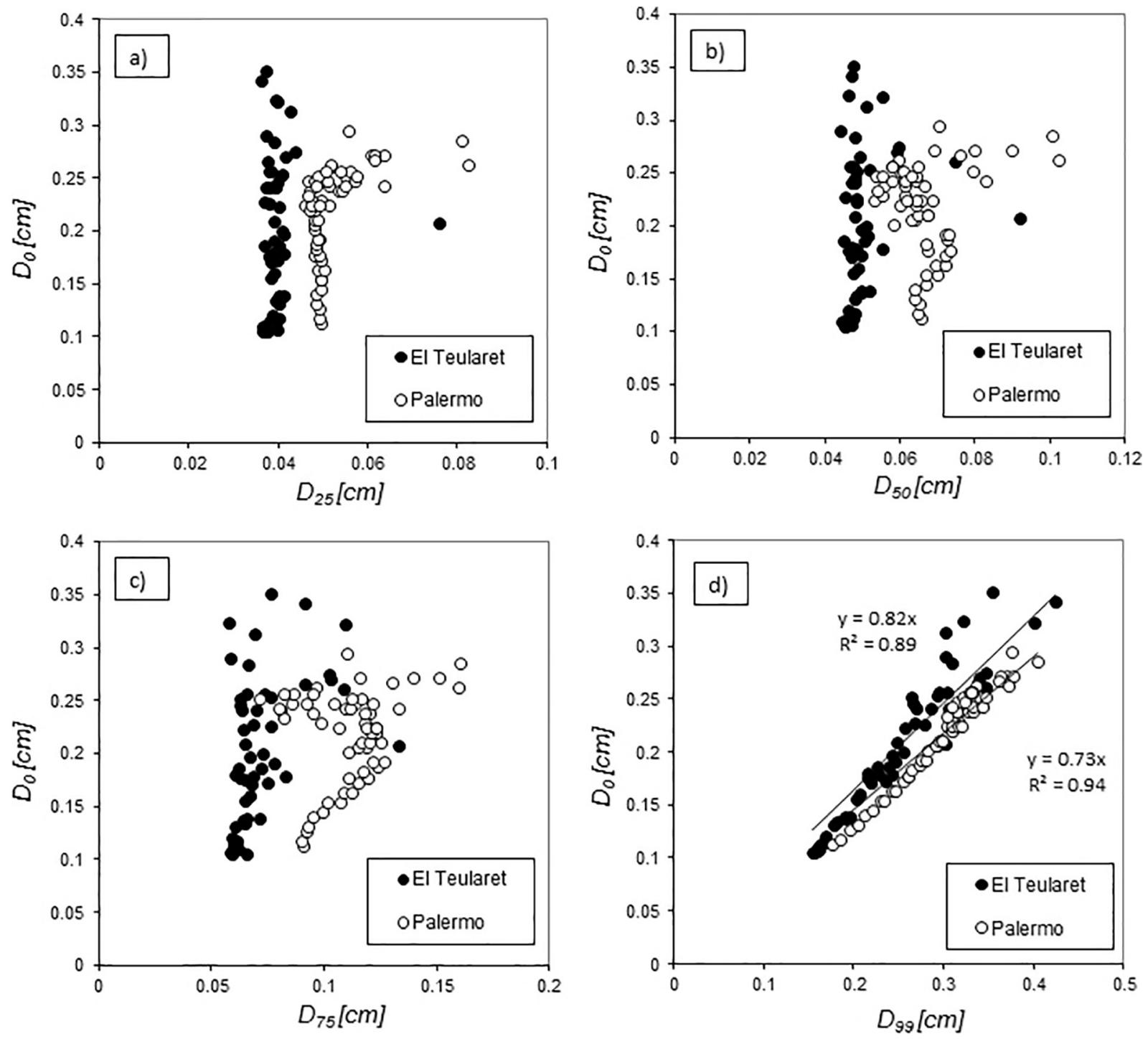

Fig. 4. Comparison between the measured $D_{0}$ values versus the characteristic diameters $\left(D_{25}, D_{50}, D_{75}\right.$ and $\left.D_{99}\right)$ of the aggregated DSDs detected at Palermo and El Teularet sites.

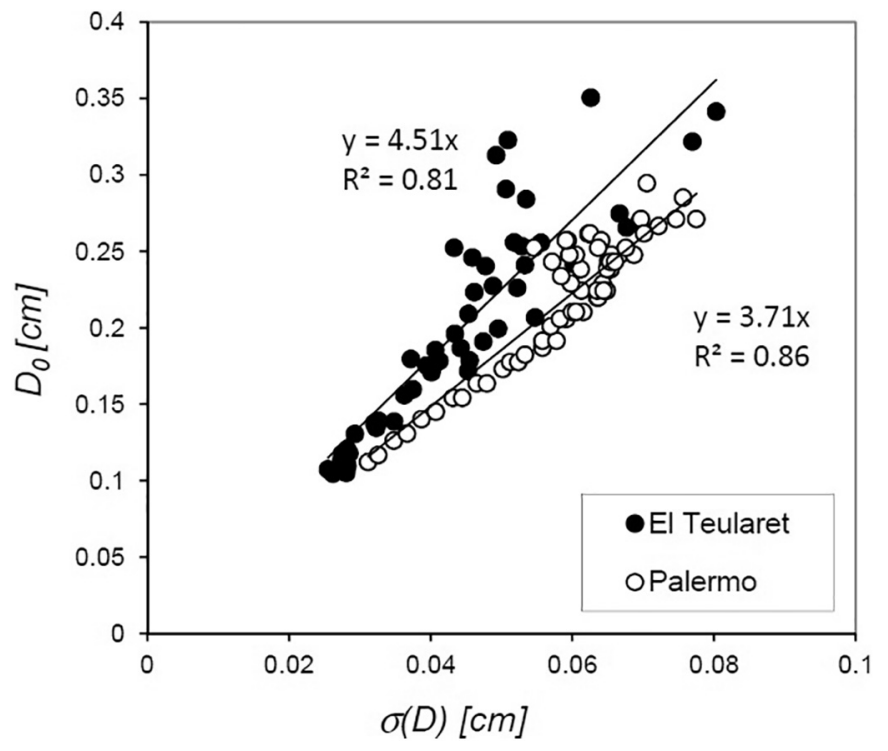

Fig. 5. Comparison between the measured $D_{0}$ values versus standard deviation $(\sigma(D))$ of the aggregated DSDs detected at Palermo and El Teularet sites. of the size of the drops because the collapse effects prevail on the disaggregation ones. The increase of drop size yields an increase of terminal velocity and, as consequence, an increase of kinetic energy per unit volume of the rainfall. Instead for $I>I_{t}$, an increase of rainfall intensity determines only an increase of number of raindrops that reach the soil without varying the drop size distribution. Probably, an equilibrium between aggregation and disaggregation phenomena occurs.

The pairs $\left(D_{0}, P_{n} / I\right)$ relative to the two datasets, plotted in Fig. 8, are overlapped and a single curve could be fitted. This circumstance demonstrates that the relationship between $P_{n} / I$ and $I$ is similar to $D_{0}-I$ one (Figs. 3 and 7) because the $P_{n} / I$ depends on the median volume diameter of the distribution (Fig. 8). The measurements of kinetic power per unit volume of rainfall carried out at Palermo and El Teularet agree with Wischmeier and Smith (1978) approach, according to which the ratio $P_{n} / I$ does not more increase with $I$ for $I>I_{t}\left(I_{t}>76 \mathrm{~mm} / \mathrm{h}\right)$ because $D_{0}$ does not continue to increase when rainfall intensities exceed the threshold value of $I$. However, in agreement to Carollo et al. (2016b) the measurements suggest a different threshold value of rainfall intensity $\left(I_{t}=40 \mathrm{~mm} / \mathrm{h}\right)$. These measurements, carried out in different Mediterranean climate and geographical contexts using the same instrument of measurement (optical disdrometer), suggest that: (i) $P_{n} / I$ depends strictly on $D_{0}$, and this relationships does not depend on the site where precipitation occurs; (ii) a good estimate of the kinetic power 

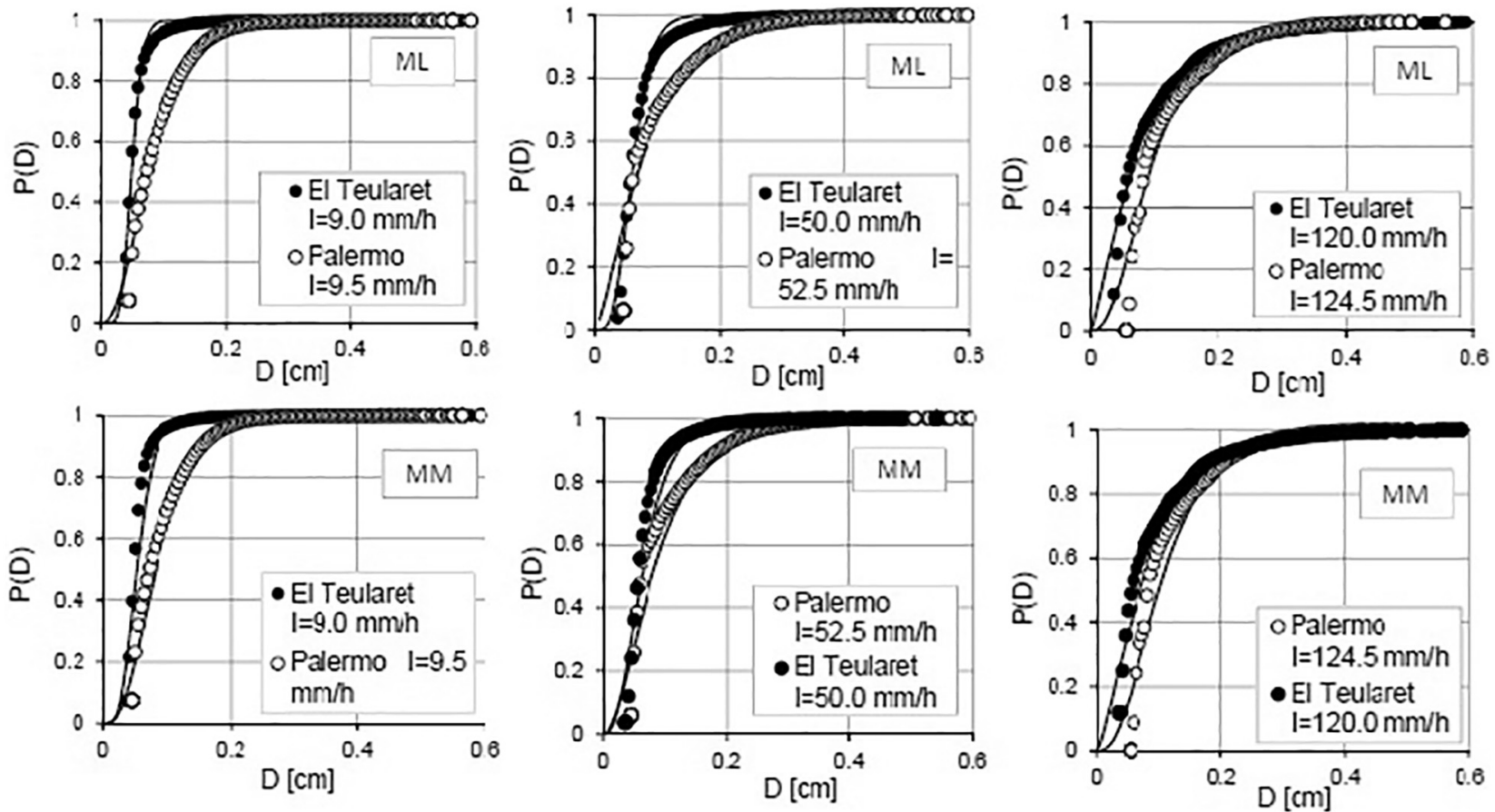

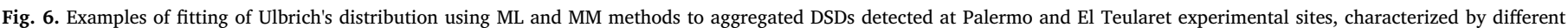
values of rainfall intensity, $I$.

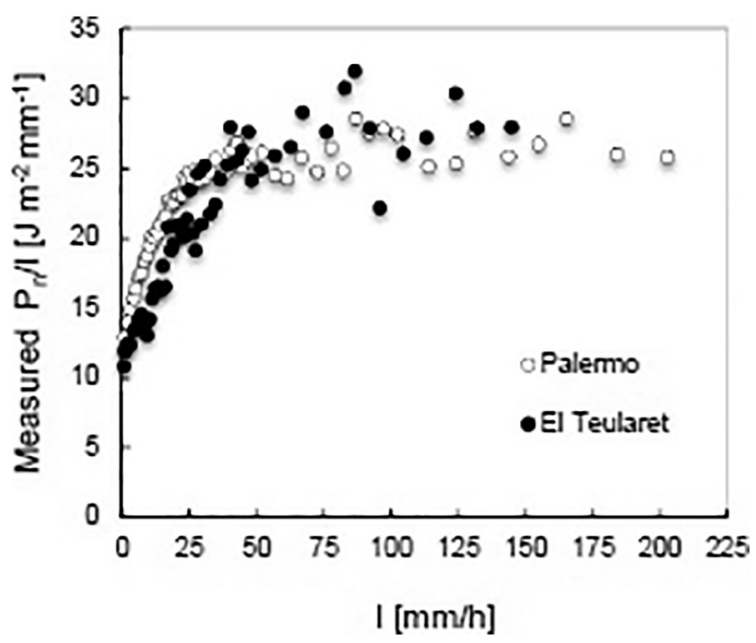

Fig. 7. Comparison between $P_{n} / I$ values versus rainfall intensity of the aggregated DSDs detected at Palermo and El Teularet sites.

per unit volume of rainfall can be obtained by a good estimate of the median volume diameter of the distribution i.e. without reproducing the whole DSD. Considering that $P_{n} / I$ depends strictly on $D_{0}$, which is correlated to the drop diameter $D_{99}$, the rainfall kinetic power per unit volume of rainfall is determined by the few raindrops characterized by the greatest values of the diameters. This result is also expected since the median volume diameter $D_{0}$ of a given DSD is determined by the rainfall volume which is proportional to the third power of the raindrop diameters. As a consequence the volume of few largest raindrops, which are basically responsible of the $P_{n} / I$ value, compensates for the volume of the smallest drops.

The kinetic power values measured in both sites were used to verify the reliability of the Eqs. (1) and (2) for kinetic power estimate by rainfall intensity at Palermo and El Teularet.

The pairs $\left(I, P_{n} / I\right)$, relative to these two experimental sites, and the curves of Eq. (1) (Fig. 9a) and Eq. (2) (Fig. 9b) using the parameter values suggested both by Brown and Foster (1987) both by McGregor

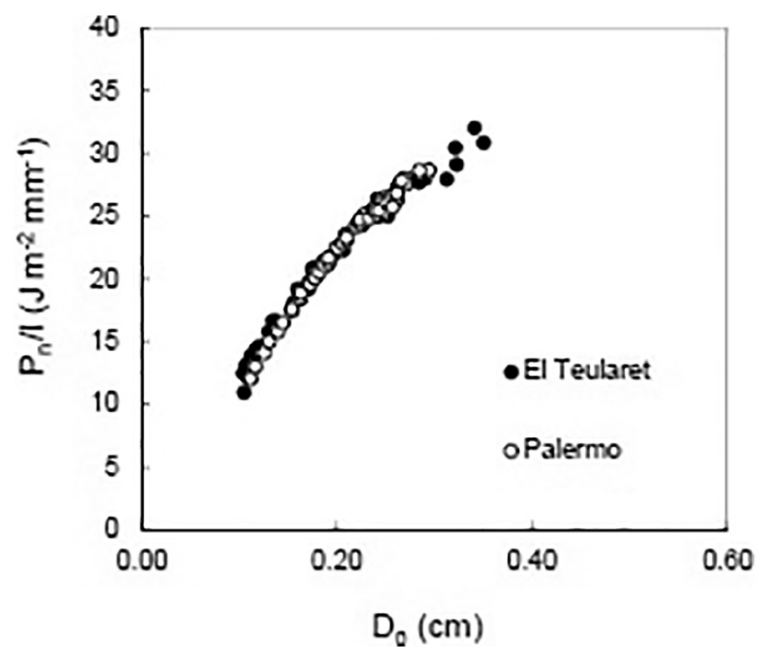

Fig. 8. Measured $P_{n} / I$ values versus median volume diameter $D_{0}$, relative to Palermo and El Teularet datasets.

et al. (1995) are represented in Fig. 9. In particular Eq. (1) proposed by Wischmeier and Smith (1978) is able to reproduce the $P_{n} / I$ values measured at Palermo experimental site for $I<40 \mathrm{~mm} / \mathrm{h}$ even if it determines a slight overestimate for $2<I<15 \mathrm{~mm} / \mathrm{h}$ and systematically overestimates the kinetic power for $I>40 \mathrm{~mm} / \mathrm{h}$. For El Teularet dataset Eq. (1) determines a systematic overestimation of the kinetic power for $I<30 \mathrm{~mm} / \mathrm{h}$ and $I>40 \mathrm{~mm} / \mathrm{h}$ (Fig. 9a). For both datasets Eq. (1) allows a more reliable $P_{n} / I$ estimate by setting $I_{t}=40 \mathrm{~mm} / \mathrm{h}$.

The reliability of Eq. (2) for estimating $P_{n} / I$ in Mediterranean environment is also tested. For Palermo dataset Eq. (2), with the parameters values proposed by Brown and Foster (1987) yields to accurate estimates of $P_{n} / I$ only for $30<I<60 \mathrm{~mm} / \mathrm{h}$ (Fig. 9b). Using of parameter values suggested by McGregor et al. (1995) yields to an underestimate the kinetic power per unit volume of rainfall for the lowest values of $I(I<10 \mathrm{~mm} / \mathrm{h})$, and to an overestimate the $P_{n} / I$ for 

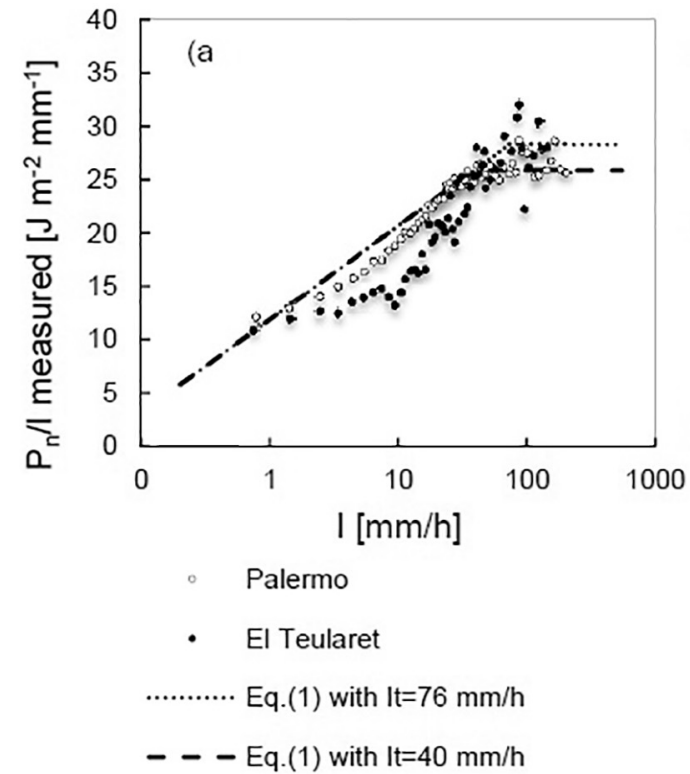

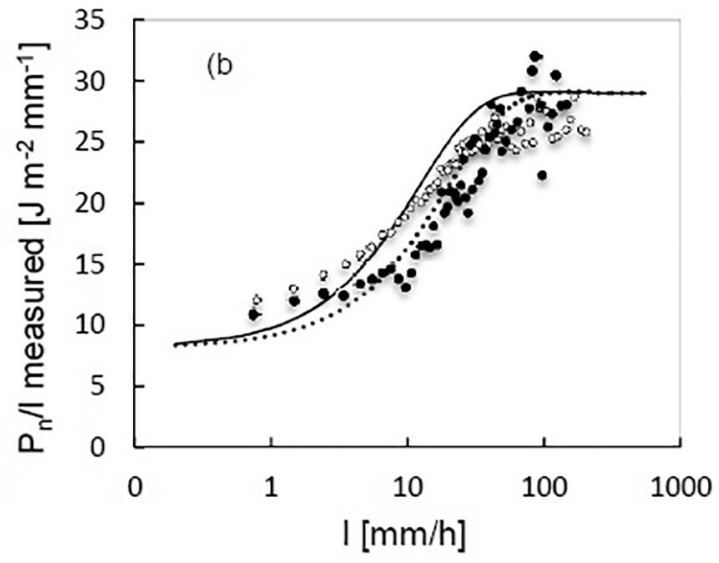

- Palermo

- El Teularet

- Eq.(2)-McGregor et al. (1995)

........ Eq.(2)-Brown and Foster (1987)

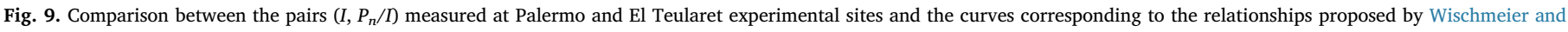
Smith (1978) with $I_{t}$ equal to76 mm/h and $40 \mathrm{~mm} / \mathrm{h}$ (a) and Kinnell (1981) with the parameters suggested by Brown and Foster (1987) and McGregor et al. (1995) (b).

$I>10 \mathrm{~mm} / \mathrm{h}$ (Fig. 9b). For El Teularet Eq. (2) with Brown and Foster (1987) parameter values yields reliable estimation of $P_{n} / I$ especially in the range $5<I<60 \mathrm{~mm} / \mathrm{h}$ (Fig. 9b). Using the parameter values suggested by McGregor et al. (1995), does not yield acceptable $P_{n} / I$ estimates by Eq. (2) (Fig. 9b).

Finally the reliability of the relationship for estimating kinetic power in different geographical location is presented using all the available measurements of $P_{n}, D_{0}, I$ (Jayawardena and Rezaur, 2000; Nyssen et al., 2005; Mueller and Sims, 1967a, b, c, 1968a, b) obtained by different measurement techniques (piezoelectric force transducer, blotting paper, drop camera and optical disdrometer). Fig. 10 shows the experimental pairs $\left(I, P_{n} / I\right)$ (Fig. 10a) and $\left(I, D_{0}\right.$ ) (Fig. 10b) of all available datasets. The scattering of the data represented in Fig. 10 confirms, in agreement with the results of Salles et al. (2002), Parsons and Gadian (2000) and Carollo et al. (2016b) that the rainfall intensity is not sufficient to establish the rainfall erosivity. In other words, the kinetic power measurements are also dependent on other parameters such as rain type, altitude, climate and method of measurement. Therefore a single relationship $P_{n}-I$, which is independent of at-site effect, like Eq. (1) or Eq. (2), is not reliable for estimating rainfall kinetic power at any site. Fig. $10 \mathrm{~b}$ highlights that the relationship $D_{0}-I$, is also site-specific, Furthermore some datasets (Mueller and Sims, 1967a, b, c, 1968a, b and present investigation), present an asymptotic trend while other measurements (Jayawardena and Rezaur, 2000; Nyssen et al., 2005) show $D_{0}$ values increasing with $I$.

For all available datasets, Fig. 11 shows the comparison between the experimental pairs $\left(D_{0}, P_{n} / I\right)$ and the theoretical relationship Eq. (19). The pairs $\left(D_{0}, P_{n} / l\right)$ are placed close to the single curve representing Eq. (19). The scattering of the pairs $\left(D_{0}, P_{n} / I\right)$, plotted in Fig. 11 , can be justified taking into account that the measurements are obtained by different techniques. These results highlight that: (i) in disagreement with Parsons and Gadian (2000) and Salles et al. (2002), the use of both variables $D_{0}$ and $I$ allows to obtain a reliable rainfall kinetic power estimate which is also at site independent; (ii) the theoretically derived Eq. (19) is applicable to all available datasets highlighting that the $P_{n} /$ $I-D_{0}$ relationship is free from at-site effects and useful to characterize rainfall erosivity in the whole wide world. These results suggest that further studies are needed to establish techniques able to provide measurements of the median volume diameter of the distribution since that at date the available instruments (i.e. impact, acoustic and optical disdrometers, piezoelectric transducer) allow to measure the whole
DSD and do not yield to a direct measurement of $D_{0}$.

\section{Conclusions}

Understanding of rainfall characteristics such as Drop Size Distribution (DSD), intensity and kinetic energy, allow to establish an indicator of rainfall erosivity useful for the prediction of soil erosion. The measurements of drop size distribution and kinetic power carried out by an optical disdrometer installed in two experimental sites (Palermo, El Telauret) characterized by different Mediterranean climate, are presented. At first the DSDs are aggregated in intensity classes differing in width, highlighting that for a fixed rainfall intensity the Palermo DSD is different from the one detected at El Teularet, being characterized by greater values of $D_{25}, D_{50}, D_{75}$ and $D_{99}$ than the El Teularet ones. For both datasets the median volume diameter of the distribution, $D_{0}$, reveals an increasing trend with rainfall intensity until a threshold value of rainfall intensity, $I_{t}$, equal to $40 \mathrm{~mm} / \mathrm{h}$. For $I>I_{t}$, $D_{0}$ does not more increase when rainfall intensity increases too. The DSD measurements allow to established that $D_{0}$ is strictly related both to the standard deviation of the rain drop size distribution both to the $D_{99}$. These results allow to conclude that: (i) the median volume diameter is also a shape parameter of the raindrop size distribution; (ii) the $D_{0}$ is affected by the greatest values of the diameters that composes precipitation.

The experimental pairs $\left(I, P_{n} / I\right)$ obtained by the two datasets are quasi-overlapped. This circumstance implies that, in the two experimental sites, characterized by different climatic and morphometric characteristics, using the same instrument of measurement, the same rainfall intensity determines different DSDs and similar kinetic power values. In particular for both datasets the ratio $P_{n} / I$ increases with rainfall intensity for $I$ less than or equal to $40 \mathrm{~mm} / \mathrm{h}$ and then it becomes quasi-constant. This trend agrees with Wischmeier and Smith (1978) approach even if the threshold value of rainfall intensity $(40 \mathrm{~mm} / \mathrm{h})$ resulted less than the one proposed by Wischmeier and Smith (1978) $(76 \mathrm{~mm} / \mathrm{h})$.

The measured kinetic power values are used for verifying in both sites the reliability of the most known empirical relationship $P_{n}-I$ which are available for estimating the kinetic power. The relationship by Wischmeier and Smith (1978) results to be reliable for estimating the kinetic power of the rainfall both in Sicilian and in Spanish environments if a threshold value of the rainfall intensity equal to $40 \mathrm{~mm} / \mathrm{h}$ has 

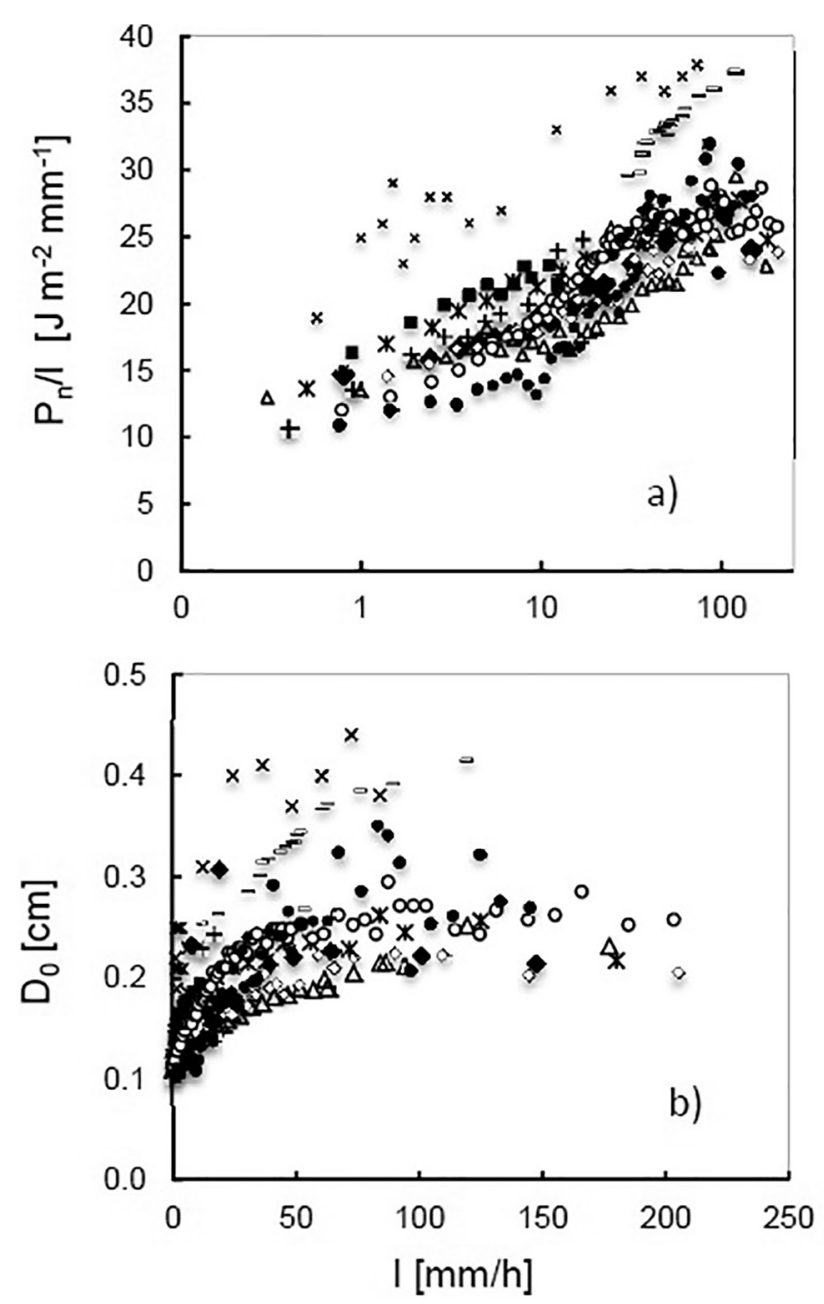

$\Delta$ Majuro Atoll - Marshall Islands (Mueller and Sims, 1967a)

- Island Beach - New Jersey (Mueller and Sims, 1967b)

+Woody Island - Alaska (Mueller and Sims, 1967c)

- Franklin- North Carolina (Muller and Sims, 1967d)

* Bogor - Indonesia (Mueller and Sims, 1968a)

- Corvallis - Oregon (Mueller and Sims, 1968b)

- Hong Kong (Jayawardena and Rezaur, 2000)

× Northern Ethiopian Highlands (Nyssen et al., 2005)

- Palermo - Sicily (present investigation)

- El Teularet (present investigation)

Fig. 10. Comparison among all available pairs $\left(I, P_{n}\right)$ (a) and $\left(I, D_{0}\right)(\mathrm{b})$ measured in different geographical sites.

to be used. For Palermo dataset Eq. (2), with the parameters values proposed by Brown and Foster (1987) yields to accurate estimates of $P_{n} / I$ only for $30<I<60 \mathrm{~mm} / \mathrm{h}$. Instead for El Teularet Eq. (2) with Brown and Foster (1987) parameter values yields accurate estimation of $P_{n} / I$ especially in the range $5<I<60 \mathrm{~mm} / \mathrm{h}$. While for both datasets considering the parameter values advanced by McGregor et al. (1995), Eq. (2) does not yield acceptable $P_{n} / I$ estimates.

Finally the experimental pairs $\left(D_{0}, P_{n} / I\right)$ corresponding to all

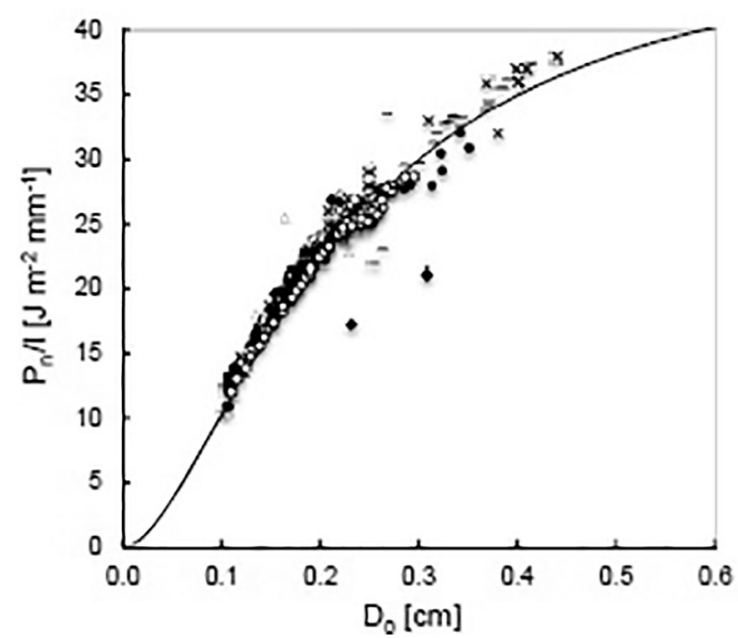

available datasets result overlapped and very close to the theoretical Eq. (19). Therefore the measurements suggest that: (i) $P_{n} / I$ depends strictly on $D_{0}$, and this relationships does not depend on the site where precipitation occurs; (ii) the median volume diameter is the centroid value of the rain drop size distribution that allows to accurately characterized the precipitation from the erosive point of view. The theoretically derived relationship is free from site effects and useful to adequately characterize the rainfall erosivity in every site of the world.

- Majuro Atoll - Marshall Islands (Mueller and Sims. 1867a)

- E Teularet (present investigation)

- Islands beach - New Jersey (Mueller and Sims. 1987b)

Woody islands - Alaska (Mueller and Sims. 1967c)

Franklin - North Carolina (Muler and Sims, 1967d)

x Bogor - Indonesia (Mueller and Sims, 1968a)

- Corvallis - Oregon (Mueller and Sims, 1968b)

- Hong Kong (Jayawiardena and Rezaur, 2000)

× Northem Ethiopian Highlands (Nyssen et al., 2005)

- Palermo - Sicily (present investigation) Eq.(19)

Fig. 11. Comparison between the experimental pairs $\left(D_{0}, P_{n} / I\right)$ relative to all available datasets and the curve corresponding to Eq. (19). 
This circumstance represents a theoretical confirmation of Wischmeier and Smith (1978) hypothesis, according to which the trend of $P_{n}-I$ depends strictly on the $D_{0}-I$ trend.

In conclusion, further studies are needed to establish new models and techniques able to provide good estimates and measurements of the median volume diameter of the distribution, since that in disagreement with Parsons and Gadian (2000) and Salles et al. (2002), the use of both the global variables $D_{0}$ and $I$ allows to estimate adequately the rainfall kinetic power independently of geographical location.

\section{Acknowledgements}

All authors set up the research, analyzed and interpreted the results and contributed to write the paper.

\section{References}

Angulo-Martínez, M., Beguería, S., Kyselý, J., 2016. Use of disdrometer data to evaluate the relationship of rainfall kinetic energy and intensity (KE-I). Sci. Total Environ. 568, 83-94. http://dx.doi.org/10.1016/j.scitotenv.2016.05.223.

Assouline, S., Mualem, Y., 1989. The similarity of regional rainfall: a dimensionless model of drop size distribution. Trans. ASAE 32 (4), 1216-1222.

Atlas, D., 1953. Optical extinction by rainfall. J. Meteorol. 10, 486-488.

Atlas, D., Ulbrich, C.W., 1977. Path- and area-integrated rainfall measurement by microwave attenuation in the 1-3 cm band. J. Appl. Meteorol. 16, 1322-1331. http:// dx.doi.org/10.1175/1520-0450(1977)016<1322:paairm > 2.0.co;2.

Baruah, P.C., 1973. An Investigation of Drop Size Distribution of Rainfall in Thailand (PhD Dissertation). Asian Institute of Technology, Bangkok, Thailand.

Beard, K.V., 1976. Terminal velocity and shape of cloud and precipitation drops aloft. J. Atmos. Sci. 33, 851-864.

Best, A.C., 1960. The size distribution of raindrops. Q. J. R. Meteorol. Soc. 76, 1636

Blanchard, D.C., 1967. From Raindrops to Volcanoes. Doubleday Garden City, New York.

Brandt, C.J., 1990. Simulation of the size distribution and erosivity of raindrops and throughfall drops. Earth Surf. Process. 15, 687-698. http://dx.doi.org/10.1002/esp. 3290150803.

Brown, L.C., Foster, G.R., 1987. Storm erosivity using idealized intensity distribution. Trans. ASAE 30, 379-386. http://dx.doi.org/10.13031/2013.31957.

Carollo, F., Ferro, V., 2015. Modeling rainfall erosivity by measured drop-size distributions. J. Hydrol. Eng. 20http://dx.doi.org/10.1061/(ASCE)HE.1943-5584.0001077. (C4014006-1-7).

Carollo, F., Ferro, V., Serio, M.A., 2016a. Estimating rainfall erosivity by aggregated drop size distributions. Hydrol. Process. 30, 2119-2128. http://dx.doi.org/10.1002/hyp. 10776.

Carollo, F., Ferro, V., Serio, M.A., 2016b. Reliability of rainfall kinetic power-intensity relationships. Hydrol. Process. 31, 1293-1300. http://dx.doi.org/10.1002/hyp. 11099.

Carter, C.E., Greer, J.D., Braud, J.H., Floyd, J.M., 1974. Raindrop characteristics in South Central United States. Trans. ASAE 17, 1033-1037. http://dx.doi.org/10.13031/ 2013.37021.

Cerdà, A., 1997. Rainfall drop size distribution in the Western Mediterranean Basin, Valencia, Spain. Catena 30 (2-3), 169-182. http://dx.doi.org/10.1016/S03418162(97)00019-2. (DOI:10.1016/S0341-8162(97)00019-2).

Cerro, C., Bech, J., Codina, B., Lorente, J., 1998. Modeling rain erosivity using disdrometric techniques. Soil Sci. Soc. Am. J. 62, 731-735.

Coutinho, M.A., Tomás, P.P., 1995. Characterization of raindrop size distributions ay the Vale Formoso Experimental Erosion Center. Catena 25, 187-197.

D'Adderio, L.P., 2015. Raindrop Size Distribution Variability From High Resolution Disdrometer Networks (Tesi di Dottorato). Università degli Studi di, Ferrara.

Epema, G.F., Riezebos, H.Th., 1983. Fall velocity of water drops at different heights as a factor influencing erosivity of simulated rain. Rainfall simulation, runoff and soil erosion. J. de Ploy Ed. Catena Suppl. 4, 1-18.

Ferro, V., 2001. Tecniche di misura e monitoraggio dei processi erosivi. In: Quaderni di Idronomia Montana, pp. 63-128 (21/2).

Fornis, R.I., Vermeulen, H.R., Nieuwenhuis, J.D., 2005. Kinetic energy-rainfall intensity relationship for Central Cebu, Philippines for soil erosion studies. J. Hydrol. 300, 20-32.

Foster, G.R., 2004. User's Reference Guide: Revised Universal Soil Loss Equation (RUSLE2). (Report USDA).

García-Orenes, F., Cerdà, A., Mataix-Solera, J., Guerrero, C., Bodí, M.B., Arcenegui, V., Zornoza, R., Sempere, J.G., 2009. Effects of agricultural management on surface soil properties and soil-water losses in eastern Spain. Soil Tillage Res. 106, 117-123. http://dx.doi.org/10.1016/j.still.2009.06.002.

Grossklaus, M., Uhlig, K., Hasse, L., 1998. An optical disdrometer for use in high wind speeds. Bull. Am. Meteorol. Soc. 1051-1059.

Gunn, R., Kinzer, G.D., 1949. The terminal velocity of fall for water droplets in stagnant air. J. Meteorol. 6, 243-248.

Hall, R.L., Calder, I.R., 1993. Drop size modification by forest canopies: Measurements using a disdrometer. J. Geophys. Res. 98, 18465-18470. http://dx.doi.org/10.1029/ 93JD01498.

Hudson, N.W., 1965. The Influence of Rainfall Mechanics on Soil Erosion. (MSc Thesis, Cape Town).
Hudson, N.W, 1971. Soil Conservation Batsford Ltd, London, pp. 338.

Jau-yau, L., Chih-Chiang, S., Tain-Fang, L., Ming-Min, G.M., 2008. Number and volume raindrop size distributions in Taiwan. Hydrol. Process. 22, 2148-2158.

Jayawardena, A.W., Rezaur, R.B., 2000. Measuring drop size distribution and kinetic energy of rainfall using a force transducer. Hydrol. Process. 14, 37-49. http://dx.doi. org/10.1002/(SICI)1099-1085(200001)14:1 < 37::AID-HYP908 > 3.0.CO;2-M.

Kelkar, V.N., 1959. Size distribution of raindrops - part II. Indian J. Meteorol. Geophys. 4, 323-330.

Kinnell, P.I.A., 1973. The problem of assessing the erosive power of rainfall from meteorological observations. Soil Sci. Soc. Am. Proc. 37, 617-621.

Kinnell, P.I.A., 1981. Rainfall intensity-kinetic energy relationship for soil loss prediction Soil Sci. Soc. Am. Proc. 45, 153-155. http://dx.doi.org/10.2136/sssaj1981. 03615995004500010033x.

Laws, J.O., 1941. Measurements of the fall velocity of water drops and raindrops. Trans. Am. Geophys. Union 22, 709-721.

Laws, J.O., Parsons, D.A., 1943. Relationship of raindrop size to intensity. Trans. Am. Geophys. Union 24, 452-459.

Lim, Y.S., Kim, J.K., Kim, J.W., Park, B.I., Kim, M.S., 2015. Analysis of the relationship between the kinetic energy and intensity of rainfall in Daejeon, Korea. Quat. Int. 384 107-117. http://dx.doi.org/10.1016/j.quaint.2015.03.021.

Marshall, J.S., Palmer, W.M.K., 1948. The distribution of raindrops with size. J. Meteorol. 5, 165-166. http://dx.doi.org/10.1175/1520-0469(1948)005<0165:TDORWS $>2$. $0 . \mathrm{CO} ; 2$.

McGregor, K.C., Bingner, R.L., Bowie, A.J., Foster, G.R., 1995. Erosivity index values for northern Mississippi. Trans. Am. Soc. Agric. Eng. 38, 1039-1047.

Meshesha, D.T., Tsunekawa, A., Tsubo, M., Haregeweyn, N., Adgo, E., 2014. Drop size distribution and kinetic energy load of rainfall events in the highlands of the Central Rift Valley, Ethiopia. Hydrol. Sci. J. 59 (12), 2203-2215. http://dx.doi.org/10.1080/ 02626667.2013.865030.

Mualem, Y., Assouline, S., 1986. Mathematical model for rain drop distribution and rainfall kinetic energy. Trans. ASAE 29 (2), 494-500.

Mueller, E.A., Sims, A.L., 1967a. Raindrop Distributions at Majuro Atoll, Marshall Islands. Research and Development Technical Report (United States. Army Electronics Command), ECOM-02071-RR1. Fort Monmouth, N.J.

Mueller, E.A., Sims, A.L., 1967b. Raindrop Distributions at Island Beach, New Jersey. Research and Development Technical Report (United States. Army Electronics Command), ECOM-02071-RR2. Fort Monmouth, N.J.

Mueller, E.A., Sims, A.L., 1967c. Raindrop Distributions at Woody Island, Alaska. Research and Development Technical Report (United States. Army Electronics Command), ECOM-02071-RR4. Fort Monmouth, N.J.

Mueller, E.A., Sims, A.L., 1968a. Raindrop Distributions at Bogor, Indonesia. Research and Development Technical Report (United States. Army Electronics Command), ECOM-02071-RR5. Fort Monmouth, N.J.

Mueller, E.A., Sims, A.L., 1968b. Raindrop Distributions at Corvallis, Oregon. Research and Development Technical Report (United States. Army Electronics Command), ECOM-02071-RR6. Fort Monmouth, N.J.

Nunes, A.N., Lourenço, L., Vieira, A., Bento-Gonçalves, A., 2016. Precipitation and erosivity in Southern Portugal: seasonal variability and trends (1950-2008). Land Degrad. Dev. 27 (2), 211-222. http://dx.doi.org/10.1002/ldr.2265.

Nyssen, J., Vandenreyken, H., Poesen, J., Moeyersons, J., Deckers, J., Haile, M., Salles, C., Govers, G., 2005. Rainfall erosivity and variability in the Northern Ethiopian Highlands. J. Hydrol. 311, 172-187. http://dx.doi.org/10.1016/j.jhydrol.2004.12. 016.

Olver, F.W.J., 1997. Asymptotics and Special Functions, A. K. Peters. (Wellesley, MA).

Parsons, D.A., Gadian, A.M., 2000. Uncertainty in modelling the detachment of soil by rainfall. Earth Surf. Process. Landf. 25, 723-728. http://dx.doi.org/10.1002/10969837(200007)25:7<723::AID-ESP127>3.0.CO;2-X.

Renard, K.G., Foster, G.R., Weesies, G.A., McCool, D.K., Yoder, D.C., 1997. Predicting soil erosion by water: a guide to conservation planning with the Revised Universal Soil Loss Equation (RUSLE). USDA 404.

Rosewell, C.J., 1986. Rainfall kinetic energy in eastern Australia. J. Appl. Meteorol. Climatol. 25, 1695-1701.

Salles, C., Poesen, J., Sempere-Torres, D., 2002. Kinetic energy of rain and its functional relationship with intensity. J. Hydrol. 257, 256-270. http://dx.doi.org/10.1016/ S0022-1694(01)00555-8.

Sauvageot, H., Lacaux, J.P., 1995. The shape of averaged drop size distributions. J. Atmos. Sci. 52, 1070-1083. http://dx.doi.org/10.1175/1520-0469(1995) $052<1070$ :TSOADS $>2.0$.CO;2.

Sempere-Torres, D., Salles, C., Creutin, J.D., Delrieu, G., 1992. Quantification of soil detachment by raindrop impact: performances of classical formulae of kinetic energy in Mediterranean storms. In: Bogen, J., Walling, D.E., Day, T. (Eds.), Erosion and Sediment Transport Monitoring Programs in River Basins. 210. International Association of Hydrological Sciences, Oslo, pp. 115-124.

Uijlenhoet, R., Stricker, J.N.M., 1999. A consistent rainfall parameterization based on exponential raindrop size distribution. J. Hydrol. 218, 101-127. http://dx.doi.org/ 10.1016/S0022-1694(99)00032-3.

Ulbrich, C.W., 1983. Natural variations in the analytical form of the raindrop size distribution. J. Clim. Appl. Meteorol. 22, 1764-1775. http://dx.doi.org/10.1175/1520 0450(1983)022<1764:NVITAF > 2.0.CO; 2 .

Van Dijk, A.I.J.M., Bruijnzeel, L.A., Rosewell, C.J., 2002. Rainfall intensity-kinetic energy relationships: a critical literature appraisal-review. J. Hydrol. 261, 1-23.

Wischmeier, W.H., Smith, D.D., 1978. Predicting rainfall erosion losses-a guide to conservation planning. In: Agriculture Handbook. United States Department of Agriculture, Washington, DC, pp. 537.

Zanchi, C., Torri, D., 1980. In: De Boodt, M., Gabriels, D. (Eds.), Evaluation of Rainfall Energy in central Italy. Assessment of Erosion. John Wiley \& Sons, Chichester, pp. 133-142. 